\title{
LIST OF SYMBOLS USED
}

ED Aus der Erfahrung des Denkens

EM Einführung in die Metaphysik

FW Der Feldweg

G Gelassenheit

HB Brief über den "Humanismus"

HD Erläuterungen zu Hölderlins Dichtung

HE "Hölderlins Himmel und Erde"

HG "Hegel und die Griechen"

HW Holzwege

ID Identität und Differenz

KM Kant und das Problem der Metaphysik

KPV Kant, Kritik der praktischen Vernunft

KRV Kant, Kritik der reinen Vernunft

$\mathrm{M} \quad Z$ u einem Vers von Mörike

N Nietzsche

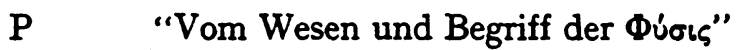

PW Platons Lehre von der Wahrheit

SF Zur Seinsfrage

SG Der Satz vom Grund

SU Die Selbstbehauptung der deutschen Universität

SZ Sein und Zeit

US Unterwegs zur Sprache

VA Vorträge und Aufsätze

WD Was heißt Denken?

WG Vom Wesen des Grundes

WM Was ist Metaphysik?

WM:Ep Was ist Metaphysik? Nachwort

WM:In Was ist Metaphysik? Einleitung

WP Was ist das - die Philosophie?

WW Vom Wesen der Wahrheit 




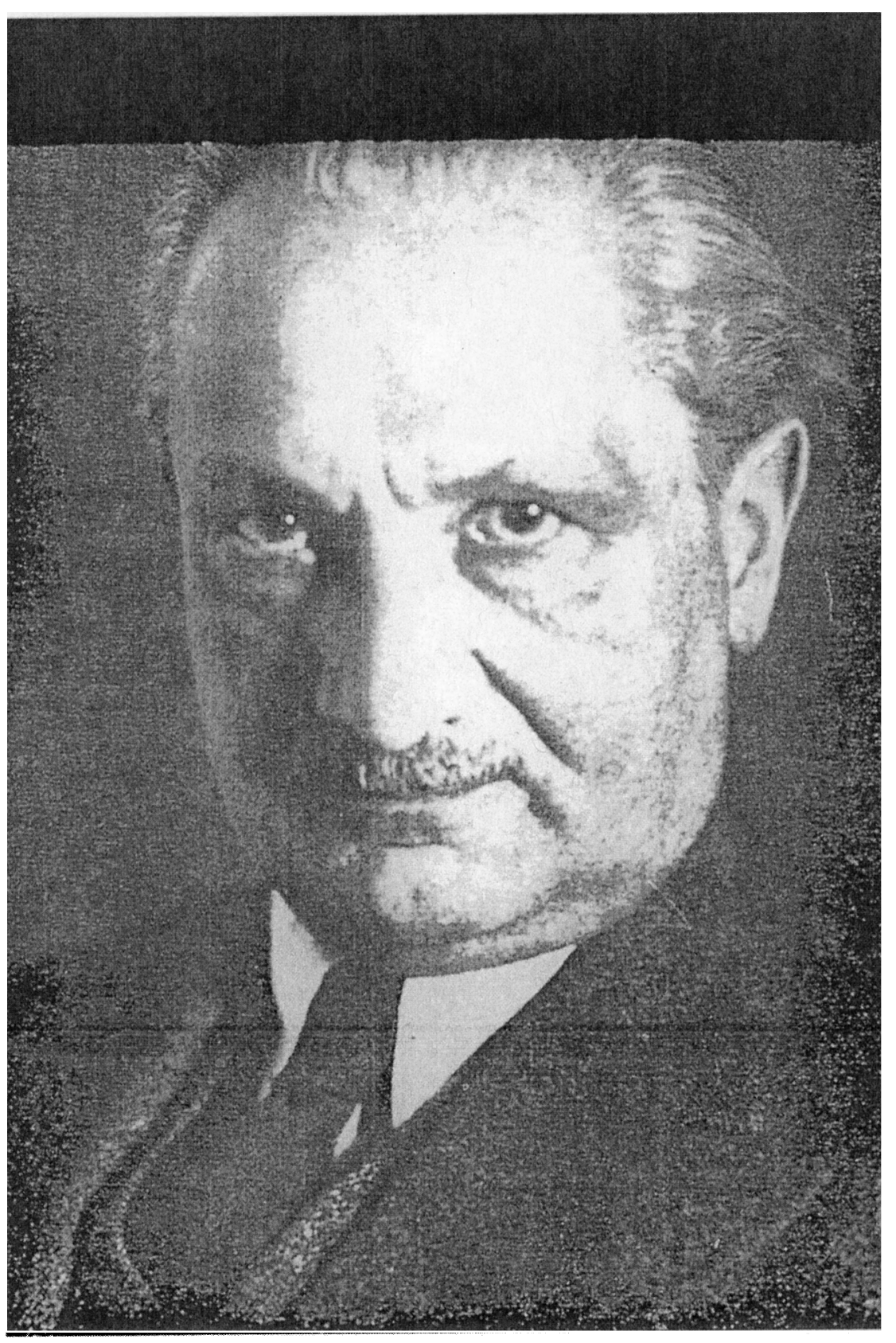

Mnstin Ynitrgyos 